\title{
Optical vortex metrology for non-destructive testing [invited]
}

\author{
Wang, W.; Hanson, Steen Grüner
}

\section{Published in:}

Conference abstract series, CLEO/Europe - EQEC

Link to article, DOI:

10.1109/CLEOE-EQEC.2009.5196307

Publication date:

2009

Document Version

Early version, also known as pre-print

Link back to DTU Orbit

Citation (APA):

Wang, W., \& Hanson, S. G. (2009). Optical vortex metrology for non-destructive testing: [invited]. In Conference abstract series, CLEO/Europe - EQEC IEEE. https://doi.org/10.1109/CLEOE-EQEC.2009.5196307

\section{General rights}

Copyright and moral rights for the publications made accessible in the public portal are retained by the authors and/or other copyright owners and it is a condition of accessing publications that users recognise and abide by the legal requirements associated with these rights.

- Users may download and print one copy of any publication from the public portal for the purpose of private study or research.

- You may not further distribute the material or use it for any profit-making activity or commercial gain

- You may freely distribute the URL identifying the publication in the public portal

If you believe that this document breaches copyright please contact us providing details, and we will remove access to the work immediately and investigate your claim 


\title{
Optical Vortex Metrology for Non-Destructive Testing
}

\author{
Wei Wang ${ }^{1,}$ and Steen G. Hanson ${ }^{2}$ \\ 1. Department of Mechanical Engineering, School of Engineering and Physical Sciences, \\ Heriot-Watt University, Edinburgh, EH14 4AS, United Kingdom \\ 2. Technical University of Denmark, OPL-128, P.O. Box 49, DK-4000 Roskilde, Denmark
}

Optical vortices or phase singularities in optical fields have been known for a long time, and their basic properties have been studied extensively since the seminal work by Nye and Berry in the early 1970s. Recently, phase singularities have come to attract new attentions for different reasons in the fields of applications such as optical metrology and photon manipulation. Because of their orbital photon angular momentum, optical vortices have proved themselves a useful means for optical trapping and manipulation of atoms and micro particles. On the contrary, phase singularities have been regarded as a nuisance by researchers in optical interferometry and profilometry, because the phase singularities hinder unique phase unwrapping of the measured phase values, which are usually wrapped into the range $[-\pi, \pi)$. Therefore, main efforts in optical metrology have been concentrated on how to get rid of the effect of phase singularities. A typical example is the phase unwrapping algorithm that directly kills out all phase singularities by superposing vortex fields with the phase singularities of opposite sign [1]. A question then naturally arises "Can phase singularities also prove themselves to be useful in optical metrology?"

The purpose of this talk is to give an answer to this question by introducing a new technique called optical vortex metrology, that makes use of the phase singularities in the pseudophase of the complex signal obtained from the Riesz transform or the Laguerre-Gauss transform of speckle patterns. Although this complex representation of real-valued speckle patterns does not introduce new information, it effectively exploits the existing information in such a manner that the newly introduced pseudoamplitude and pseudophase associated with the complex signal provide a powerful means for analyzing, processing and understanding the available information from the recorded speckle pattern. Furthermore, because the pseudophase can be detected without recourse to interferometry and the principle is based on tracing individual phase singularities as displacement markers, the proposed technique has the versatility that expands applications beyond those known for conventional correlation-based laser speckle metrology. Here, we will review the principle and demonstrate how effective use can be made of optical vortices or phase singularities for displacement [2-3], flow measurements [4] and biological kinematic analysis [5].
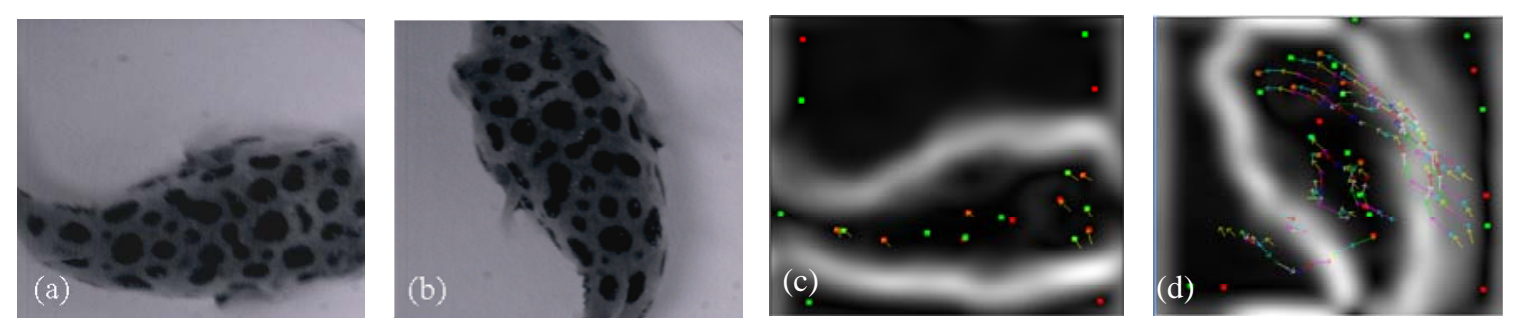

Fig. 1 Recorded images for the swimming fugu at different instants of time and the corresponding trajectory of phase singularities; (a) and (c) are recorded at $\mathrm{t}=0.70$ seconds; (b) and (d) at $\mathrm{t}=3.33$ seconds.

\section{References}

[1] M. Takeda, "Recent developments in phase unwrapping techniques,” Optical Inspection and Micromeasurements (Besancon, France) C. Gorecki Ed., Proc. SPIE 2782, 334 (1996).

[2] W. Wang, T. Yokozeki, R. Ishijima, A. Wada, S. G. Hanson, Y. Miyamoto, and M. Takeda, “Optical vortex metrology for nanometric speckle displacement measurement,” Opt. Express 14, 120 (2006).

[3] W. Wang, T. Yokozeki, R. Ishijima, S. G. Hanson, and M. Takeda, "Optical vortex metrology based on the core structures of phase singularities in Laguerre-Gauss transform of a speckle pattern,” Opt. Express 14, 10195 (2006).

[4] W. Wang, M. R. Dennis, R. Ishijima, T. Yokozeki, A. Matsuda, S. G. Hanson, and M. Takeda, "Poincaré sphere representation for the anisotropy of phase singularities and its applications to optical vortex metrology for fluid mechanical analysis,” Opt. Express 15, 11008 (2007).

[5] W. Wang, Y. Qiao, R. Ishijima, T. Yokozeki, D. Honda, A. Matsuda, S. G. Hanson, and M. Takeda, “Constellation of phase singularities in a specklelike pattern for optical vortex metrology applied to biological kinematic analysis,” Opitcs Express 16, 13908 (2008). 